\title{
Experiencias en la intervención con el entorno facilitador de la autonomía personal
}

\section{Experiences in the intervention with accessible environments to facilitate personal autonomy}

\section{Cristina RODRÍGUEZ-PORRERO MIRET*}

\section{RESUMEN}

Con el fin de llevar una vida independiente y participar plenamente en la sociedad, es imprescindible que los entornos cumplan criterios de Accesibilidad y Diseño para Todos. La evolución desde el concepto de eliminación de barreras arquitectónicas a la idea de diseñar desde el principio pensando en todos, ha tenido en España un proceso semejante al de otros paises. Un gran número de estudios, servicios y experiencias han sido exitosas en demostrar la necesidad de un mayor grado de accesibilidad en viviendas, edificios públicos y webs. La accesibilidad, la usabilidad, la calidad y la sostenibilidad son claves importantes en las politicas europeas y nacionales, ofreciendo buenas oportunidades a nuevos mercados y servicios, nuevos desarrollos curriculares y mayor creatividad para muchos profesionales.

\section{PALABRAS CLAVE}

Diseño para Todos, Usabilidad, Vida Independiente, Curriculum, Derechos, Sostenibilidad, Creatividad.

\section{ABSTRACT}

Accessible and designed for all environments are necessary to live independently and have full participation in social life. The evolution from the concept of architectural barriers to the idea of designing for all has been similar in Spain to other countries. Studies, servi-

* Directora del Centro Estatal de Autonomía Personal y Ayudas Técnicas (CEAPAT), Instituto de Mayores y Servicios Sociales (IMSERSO), Ministerio de Trabajo y Asuntos Sociales. 
Experiencias en la intervención con el entorno facilitador de la autonomía personal

ces and experiences have been successful to prove the necessity of better accessibility in homes, public buildings and webs. Accessibly, usability, quality and sustainability are in a high position in the European and national political agendas, offering good opportunities for new markets and services, new curricula and more creativity for many professionals.

\section{KEY WORDS}

Design for All, Usability, Independent Living, Curricula, Rights, Sustainability Creativity. 
La diversidad es una característica de la humanidad. El Diseño para Todos o Diseño Universal consiste en la percepción y creación de entornos, productos, tecnologías y servicios de manera que puedan ser utilizados por el mayor número posible de personas, sin necesidad de adaptaciones o soluciones específicas.

La filosofía del Diseño para Todos se ajusta a los deseos y expectativas de las personas con diversidad funcional, 0 personas con discapacidad, de llevar una vida independiente, gozar de autonomía y participar directamente en la sociedad. Crecer con nuestras familias en nuestros hogares, asistir al colegio del vecindario, viajar en el mismo autobús, encontrar y mantener un trabajo acorde con nuestros estudios y habilidades y tener la oportunidad de promocionar, son expectativas que todos tenemos. Sin embargo si los entornos no están diseñados para ser utilizados por personas con diversidad funcional: usuarios de silla de ruedas, personas de talla baja, personas usuarias de ayudas técnicas para la comunicación o personas usuarias de lengua de signos, se está impidiendo el disfrute de derechos como ciudadanos.

Cuando los diseñadores, arquitectos, ingenieros y prestadores de servicios tienen empatía con la condición humana, ven la vida en toda su amplitud y cuando reconocen que cada persona, independientemente de su situación, merece una respuesta de diseño adecuado, nos estamos acercando a la universalidad del diseño.

Se comprueba con firmeza que un buen diseño capacita y un mal diseño discapacita. Determinada situación o entorno pueden resultar discapacitantes para cualquier persona, dificultando 0 impidiendo su uso provechoso. Diseñar pensando en las personas que tienen mayores dificultades, resulta en un buen diseño para cualquier usuario.

Los principios del Diseño para Todos facilitan:

- Sentirse seguro y libre.

- Entender la información y lo que ocurre en el entorno.

- Saber donde se está y estar a gusto donde se está.

- Celebrar lo que uno puede hacer, no lo que no puede hacer.

El termino "Diseño Universal" fue utilizado por primera vez en EE.UU. por Ronald R. Mace en 1985, arquitecto de reconocido prestigio, diseñador, profesor y usuario de silla de ruedas. Su trabajo fue pionero en el diseño accesible, participó en la elaboración de la Ley de Americanos con Discapacidad (ADA) fundó el Centro de Diseño Universal en 1989 y celebró la Primera Conferencia Internacional de Diseño para Todos.

La evolución en España y en la mayoría de los países hasta llegar al principio de Diseño para Todos ha tenido tres fases fundamentales:

- Percepción de la existencia de barreras. Politicas para la "eliminación de barreras". Predominio de la atención a personas con discapacidad física.

- Ampliación al concepto de "Accesibilidad Universal". Las barreras a la comunicación y al transporte, se incluyen junto con las barreras físicas, y se globaliza la accesibilidad.

- Concepto de Diseño para Todos. Se comprueba que un buen diseño 
para personas con discapacidad es bueno para la mayoría de los ciudadanos. No se trata ya de eliminar barreras sino de no crearlas, y diseñar desde el inicio con criterios de accesibilidad, usabilidad, calidad y sostenibilidad. Se incluyen las telecomunicaciones, y las nuevas tecnologias. Se incorpora la accesibilidad electrónica como criterio para alcanzar la inclusión electrónica y la participación en la Sociedad de la Información.

Desde el Centro Estatal de Autonomía Personal y Ayudas Técnicas del IMSERSO se han realizado un gran número de publicaciones, programas, asesoramientos y experiencias positivas dirigidas a conseguir entornos facilitadores desde la perspectiva de la Accesibilidad Universal y el Diseño para Todos. En ello han contribuido arquitectos, psicólogos, ingenieros, terapeutas ocupacionales, trabajando en equipo con otros muchos agentes.

De todas estas experiencias seleccionamos tres de ellas: Viviendas Accesibles, Centros Públicos Accesibles y Accesibilidad y Usabilidad de la Web.

\section{Viviendas Accesibles}

La vivienda es el espacio edificado en el que consumimos la mayor parte de nuestro tiempo, aquel del que tenemos mas dependencia, pues nos proporciona abrigo, privacidad y, en general, bienestar. Pero la vivienda también se puede convertir en un elemento de aislamiento, inseguridad o malestar, sino ofrece un grado suficiente de accesibilidad y funcionalidad, sobre todo para aquellas personas cuyos requerimientos son mayores: las personas con discapacidad. Para ellos la distribución interior y la comunicación vivienda-calle constituyen un cúmulo de barreras, a las que seguirán otras: transporte, trabajo y ocio. Sin accesibilidad en, desde y hasta la vivienda no es posible, o es muy dificil, realizar actividades fuera de ellas.

Desde el Area de Accesibilidad del CEAPAT se desarrolla un servicio de asesoramiento y formación para arquitectos y diseñadores, participando intensamente en desarrollos legislativos, normativos, códigos técnicos, y en la publicación de documentos, guias y manuales.

A la vez se realiza un sistema de apoyo directo a usuarios con discapacidad que requieren adaptar su vivienda con criterios de accesibilidad. Para acceder a este apoyo se ha elaborado un sistema de trabajo que permite con calidad y eficacia llegar al mayor numero posible de usuarios demandantes.

Para acceder al servicio se requiere una petición a través de un organismo público: Ayuntamiento, Diputaciơn, Centro Base, Centro de tercera edad, Hospital, etc. Con ello se pretende que la necesidad de adaptación de viviendas sea conocida por los responsables y trabajadores de los recursos existentes cercanos al usuario, y desde alli se deriven a un centro especializado. Ello ha permitido un dialogo muy fluido con médicos, trabajadores sociales, psicólogos y otros profesionales relacionados con el campo de la discapacidad.

Las consultas pueden ser telefónicas, vía correo electrónico, presenciales en el Centro y con visita al domicilio.

Las dificultades encontradas en muchas viviendas por personas en situación de dependencia llevan a un mayor conocimiento sobre criterios de accesibilidad integral en la edificación.

El Libro Verde de la Accesibilidad establece que los elementos con mayores 
dificultades en el interior de la vivienda, son los cuartos de baño, pasillos y en el acceso a la vivienda, escaleras y ascensores estrechos.

En la encuesta realizada a personas sin discapacidad sobre la falta de accesibilidad en la vivienda se comprueba que las dificultades encontradas tienen características muy semejantes a las que encuentran las personas con discapacidad: dificultad de subir peldaños con silla de bebé, carros de compra, mala distribución, puertas estrechas, ... Esta situación reconocida, por la población con y sin discapacidad, nos lleva a un nuevo concepto de vivienda, más accesible y sostenible. Así el nuevo Código de Edificación establece una serie de exigencias de accesibilidad en las nuevas edificaciones de vivienda.

Para realizar las necesarias adaptaciones de viviendas, que no se construyeron en su dia con estos criterios de accesibilidad, se van generando apoyos financieros desde los ayuntamientos, diputaciones y administración central. El proyecto de Ley de Promoción de la Autonomía y Atención a la Dependencia establece en su Disposición adicional tercera "La Administración General del Estado y las Comunidades Autónomas podrán, de conformidad con sus disponibilidades presupuestarias, establecer acuerdos específicos para la concesión de ayudas económicas con el fin de facilitar la autonomía personal.

Estas ayudas tendrán la condición de subvención e irán destinadas:

a) A apoyar a la persona con ayudas técnicas o instrumentos necesarios para el normal desenvolvimiento de su vida ordinaria.

b) A facilitar la eliminación de barreras arquitectónicas y adaptaciones en el hogar que contribuyan a mejorar su capacidad de desplazamiento en la vivienda".

Con el fin de garantizar viviendas accesibles, sostenibles y adaptables a las distintas necesidades de sus habitantes se requieren fundamentalmente las siguientes medidas:

- Formación en Diseño para Todos en los curriculums de los diferentes profesionales.

- Completar y armonizar el marco legal, estableciendo mecanismos efectivos de control y seguimiento.

- Normativa técnica, reglamentos y estándares.

- Exigencia de condiciones de accesibilidad en contratos públicos.

- Presión de los consumidores y usuarios.

- Concienciación de constructores y empresarios.

- Estudios sobre el coste de las barreras y los beneficios de la accesibilidad.

- Mayores servicios y financiación para la adaptación de viviendas.

- Elaboración de guías practicas.

- Mercado transparente.

\section{Centros Públicos Accesibles}

El acceso a los servicios públicos y la participación en acciones politicas, culturales, de ocio y de acción ciudadana, 
exige un diseño plenamente accesible que no deje fuera a un gran numero de personas con diversidad funcional.

La Ley 51/2003 de igualdad de oportunidades no discriminación y accesibilidad universal de las personas con discapacidad, las legislaciones estatales y autonómicas de accesibilidad, las normas y códigos técnicos y el Plan Nacional de Accesibilidad 2004-2012, suponen importantes herramientas a favor del aseguramiento de la accesibilidad en espacios públicos.

Desde el CEAPAT se han realizado números asesoramientos a centros públicos con el fin de asegurar la accesibilidad: centros sociales y culturales, edificios y oficinas de las administraciones públicas, museos, universidades, centros de formación, centros hospitalarios y sanitarios, entre otros.

Los edificios de uso público pertenecientes a las Administraciones Públicas deben reunir condiciones particularmente exigentes de accesibilidad por dos razones fundamentales:

- La necesidad de ofrecer igualdad de oportunidades de acceso a los bienes y servicios públicos para todas las personas.

- Su carácter ejemplificador para toda la sociedad en cuanto al cumplimiento de normativa legal y técnica y la adaptación a las necesidades de todos los ciudadanos.

En las evaluaciones realizadas para la preparación del Plan de Accesibilidad, a través del Libro Verde y el Libro Blanco de la Accesibilidad, durante los años 2000-2003, los edificios administrativos han sido los que han presentado mayor número de barreras, lo que contrasta con su esencia y cometidos, pues deben prestar un servicio sin discriminación para todos los ciudadanos.

El desarrollo de la Ley 51/2003 sobre igualdad de oportunidades, no discriminación y accesibilidad universal de las personas con discapacidad, ha supuesto la elaboración de unas condiciones básicas de accesibilidad en las oficinas públicas.

Este trabajo se ha desarrollado por un grupo de expertos de las diferentes administraciones, profesionales, y la imprescindible participación del Comité Español de Representantes de Personas con Discapacidad (CERMI).

El resultado obtenido en este grupo de trabajo, en el que el CEAPAT ha participado activamente, ha servido para establecer los criterios que una oficina publica debe cumplir para ser accesible y utilizable en igualdad de condiciones y sin discriminación.

La accesibilidad incluye el acceso a la oficina desde la calle; el espacio interior; las áreas de circulación horizontal; y las áreas de circulación vertical; los espacios de recepción y estanciales; los elementos de información; la señalización; el mobiliario; los espacios higienico-sanitarios; zonas de descanso, ocio y recreación; la prevención de riesgos, avisos de emergencia; la iluminación; las superficies; la información y comunicación (directa, en texto, telefónica, electrónica,..), las actitudes y formación del personal.

Pero además de todos los criterios para el usuario externo, las oficinas deben ser accesibles para los usuarios internos, los propios trabajadores con discapacidad. Este aspecto debe ser tenido en cuenta al planificar una oficina publica teniendo en cuenta desde el inicio criterios de accesibilidad y usabilidad 
para usuarios externos e internos con diversidad funcional.

\section{Accesibilidad y usabilidad de las Web}

El acceso a la información y a la comunicación a través de la red es en la actualidad una rutina en la vida diaria. Pero muchas personas con discapacidad encuentran muy dificil o imposible acceder a la información e intercambiarla, aunque sean actividades que la mayoria de nosotros damos por hecho.

Las personas con discapacidad y personas mayores no pueden disfrutar de las ventajas de las tecnologias de la información y comunicación, si estas no cumplen criterios de accesibilidad y usabilidad. Estas tecnologias suponen herramientas muy poderosas para el desarrollo personal, la participación social, el crecimiento y el empleo.

Las politicas europeas y nacionales reconocen la importancia del acceso por parte de personas con discapacidad y personas mayores a las Tecnologías de la Información y Comunicación (TIC).

La Accesibilidad a la Web supone un aspecto esencial de una Sociedad de la Información Inclusiva, sin discriminación, que evite la brecha digital.

La accesibilidad a la web es el acceso a la red independientemente del tipo de dispositivo, infraestructura, software, idioma, cultura, localización geográfica y capacidades de los usuarios.
Los sitios web accesibles benefician a todas las personas al asegurar la posibilidad y facilidad de navegación.

Es un derecho de las personas con discapacidad poder acceder a Internet en igualdad de condiciones y de manera autónoma. Garantizar el acceso a Internet para todos, es, además, una obligación legal para las Administraciones Publicas $^{1}$.

Una nueva web debe ser diseñada desde el inicio con criterios de accesibilidad.

Si ya se dispone de una web conviene revisar cual es su nivel de accesibilidad para poder detectar fallos y corregirlos.

Para el desarrollo de criterios de accesibilidad contamos con herramientas muy eficaces: como las Directrices de Accesibilidad elaboradas por el Consorcio World Wide Web².

En el CEAPAT hemos diseñado un "kit" de accesibilidad a la web ${ }^{3}$, que contiene información relevante para el diseño y mantenimiento de webs accesibles. Así mismo hemos promovido una prueba de accesibilidad, un test en castellano para revisar el cumplimiento de las directrices de accesibilidad ${ }^{4}$. Este test se ha visto complementado por una herramienta destinada a la formación, información y validación electrónica de los sitios web ${ }^{5}$.

El concepto de usabilidad está muy ligado al de accesibilidad e implica disenar facilitando la navegación ofreciendo información que sea comprensible y

\footnotetext{
${ }^{1}$ Ley $34 / 2002$ de Servicios de la Sociedad de la Información y el Comercio Electrónico y Ley 51/2003 de igualdad de oportunidades, no discriminación y accesibilidad universal para personas con discapacidad.

${ }^{2}$ World Wide Web Consortium. www.w3.org

${ }^{3}$ Kit de Accesibilidad a la Web. www.e-kaw.org

${ }^{4}$ Test de Accesibilidad Web TAW. www.tawdis.net

${ }^{5}$ Pista accesibilidad. www.pistaccesibilidad.org
} 
manejable, y ayudando al usuario a interacturar con mayor efectividad.

Para las personas mayores y para las personas con diversidad funcional una red accesible y usable puede contribuir en gran manera a su autonomía personal y su participación activa en la sociedad.

La Psicología debe cumplir la función de facilitadora y posibilitadora de una mejor adecuación entre en entorno y la persona, sea este un entorno construido o electrónico, y sea cualquiera la diversidad funcional de la persona.

El camino para conseguir una plena accesibilidad y avances significativos en el diseño para todos, aspectos imprescindibles en una sociedad inclusiva y digna, exige mayor dedicación de los/las psicólogos/as a estos campos, aportando conocimiento y creatividad.

\section{BIBLIOGRAFÍA}

Alonso López, F. (1999). Los beneficios de renunciar a las barreras. Análisis económico de la demanda de accesibilidad arquitectónica en las viviendas. Madrid: Ministerio de Trabajo y Asuntos Sociales. Secretaría General de Asuntos Sociales. Instituto de Migraciones y Servicios Sociales.

Consejo Nacional de Discapacidad de EE.UU. (2001). El futuro accesible. Madrid: Escuela Libre de Derecho y Economía.

Dirección General de la Vivienda y la Arquitectura e Instituto de Migraciones y Servicios Sociales (2002). Guía técnica de accesibilidad en la edificación 2001. Madrid: Ministerio de Fomento, 2a ed.

García Alonso, J.V. (coord.) (2005). ¡Pregúntame sobre accesibilidad y ayudas técnicas!. Madrid: Instituto de Biomecánica de Valencia, Centro Estatal de Autonomía Personal y Ayudas Técnicas y ALIDES.

Guerrero Vega, J.M. et al. (1995). Manual de accesibilidad. Madrid: Ministerio de Trabajo y
Asuntos Sociales. Instituto de Migraciones y Servicios Sociales.

Instituto de Mayores y Servicios Sociales (2004). Plan Nacional de Accesibilidad 2004-1012. Madrid: Ministerio de Trabajo y Asuntos sociales. Secretaría de Estado de Asuntos sociales, Familias y discapacidad. Instituto de Mayores y Servicios Sociales.

Juncá Ubierna, J.A. (2000). Accesibilidad universal. Diseño sin discriminación. Madrid: Ministerio de Trabajo y Asuntos Sociales. Secretaría General de Asuntos Sociales. Instituto de Migraciones y Servicios Sociales.

Maraña, J.J. et al. (1999). Vida independiente, buenas prácticas. Madrid: Instituto de Mayores y Servicios Sociales.

Preiser, W.F.E. y Ostroff, E. (ed.) (2001). Universal Design Handbook. Nueva York: McGraw-Hill.

Rodríguez-Porrero, C. (2002). "Características, origen y retos del Diseño para Todos". Revista Minusval, nº 133, Marzo-Abril, 17-20. 